\title{
Gestão de Custos em Escola de Idiomas: Estudo de Caso com aplicação da Análise Custo/Volume/Lucro
}

\begin{abstract}
Rodney Wernke
Doutorado em Engenharia de Produção pela Universidade Federal de Santa Catarina UFSC Professor da Universidade do Sul de Santa Catarina - UNISUL E-mail: rodneywernke1@hotmail.com

Lucas dos Santos Faccenda E-mail: lucasfyazigi@gmail.com

Doutorado em Engenharia de Produção pela Universidade Federal de Santa Catarina -

Ivone Junges Professora da Universidade do Sul de Santa Catarina - UNISUL E-mail: ivone.junges@unisul.br
\end{abstract}

\section{RESUMO}

O artigo relata estudo de caso sobre a aplicação da Análise Custo/Volume/Lucro (CVL) em escola de idiomas. Buscou resposta para questão relacionada às informações gerenciais proporcionadas pela Análise CVL nesse tipo de estabelecimento e teve 0 objetivo de identificar as informações gerenciais que podem ser obtidas por meio dessa ferramenta nesse contexto empresarial. Quanto à metodologia, caracteriza-se como descritiva, com abordagem qualitativa e utilização do procedimento de estudo de caso. No que tange aos resultados, a pesquisa demonstrou que a utilização da Análise CVL permitiu aos administradores da entidade a obtenção de diversas informações de cunho gerencial que não dispunham até então. Ou seja, possibilitou conhecer a rentabilidade de cada turma individualmente; apurar quais turmas contribuíram mais para o resultado do período; determinar o ponto de equilíbrio das operações da escola e por turma (em valor monetário e em número de mensalidades); identificar a margem de segurança do negócio; elaborar uma demonstração do resultado em formato gerencial e mensurar a lucratividade mensal evidenciando a participação percentual de cada fator no resultado. Ao término da pesquisa, concluiu-se pela aplicabilidade da Análise CVL nesse tipo de instituição de ensino, sem maiores adaptações para adequação ao contexto visado.

Palavras-chave: Escola de idiomas. Análise CVL. Estudo de caso. 
Gestão de Custos em Escola de Idiomas: Estudo de Caso com aplicação da Análise

Custo/Volume/Lucro

Rodney Wernke, Lucas dos Santos Faccenda, Ivone Junges

\title{
Management of Costs in Language School: Case Study With application of Cost/Volume/Profit Analysis
}

\begin{abstract}
The article reports a case study on the application of Cost/Volume/Profit Analysis (CVP) in a language school. It sought a response to a question related to the managerial information provided by the CVP Analysis in this type of establishment and had the objective of identifying the managerial information that can be obtained through this tool in this business context. As for the methodology, it is characterized as descriptive, with a qualitative approach and used the case study procedure. Regarding the results, the research showed that the use of the CVP Analysis allowed the managers of the entity to obtain several management information that they did not have until then. That is, made it possible to know the profitability of each class individually; to determine which classes contributed most to the result of the period; determine the break-even point of the school's operations and per class (in monetary value and number of monthly payments); identify the safety margin of the business; prepare a statement of results in a managerial format and measure the monthly profitability showing the percentage participation of each factor in the result. At the end of the study, it was concluded that the CVP Analysis is applicable in this type of teaching institution without major adaptations to fit the context.
\end{abstract}

Keywords: Language school. CVP Analysis. Case study.

\section{INTRODUÇÃO}

Aspectos como a facilidade de acesso à internet e a globalização econômica têm incentivado a procura pelo aprendizado de outros idiomas no Brasil. Nesse sentido, $5,1 \%$ da população brasileira de 16 anos ou mais afirmam possuir algum conhecimento do idioma inglês. Porém, existem diferenças entre as gerações, pois entre os mais jovens (18 a 24 anos), o percentual dos que afirmam falar inglês dobra, chegando a 10,3\% das pessoas nessa faixa etária (Instituto de Pesquisas Data Popular, 2014).

Esse interesse por outros idiomas é um fator que estimula o surgimento de escolas de idiomas no país, o que acaba por acirrar a concorrência nesse nicho de mercado. Acerca disso, Eberle e Colauto (2015) citam que as organizações, de modo geral, estão sujeitas às pressões ambientais, e o mercado cada vez mais concorrido 
requer posturas ativas por parte dos administradores, aliadas à necessidade de um processo de gestão para a tomada de decisões mais ágil e eficiente.

Para fazer frente a esse aumento da competição, cabe aos gestores dessas instituições de ensino, franqueadas ou não, gerenciarem seus custos de modo a otimizarem o resultado. Porém, nos empreendimentos de pequeno porte desse segmento, a gestão costuma ficar a cargo de profissionais com formação em Pedagogia ou Letras, que tendem a priorizar aspectos operacionais e pedagógicos em detrimento da gestão econômico-financeira.

Acerca disso, Cunha (1999) aduz que se espera cada vez mais que o professorgestor desempenhe uma gama de atividades concomitantes ao ensino, tais como as de cunho administrativo, de líder educacional, de representante da instituição, de coordenação, entre outras. Mas, de acordo com Santos e Bronnemann (2013), a eficácia na execução das atividades de gestão nem sempre ocorre, pois nas instituições de ensino os gestores normalmente são docentes que assumem seus cargos sem conhecimento gerencial anterior, o que pode acarretar díspares dificuldades.

Mesmo que essa característica gerencial seja uma realidade presente na maioria das micro e pequenas empresas brasileiras, independentemente do segmento de atuação (Peleias, 2011; Padoveze \& Takakura Júnior, 2013), determinadas ferramentas gerenciais não deveriam deixar de ser utilizadas nesse contexto empresarial. É o caso da Análise Custo/Volume/Lucro (CVL), cujos benefícios informativos (como a análise da lucratividade de segmentos de mercado, a determinação do ponto de equilíbrio operacional ou econômico e a simulação de cenários em termos de preços, custos, volumes e lucros, entre outras informações úteis), são ressaltados na literatura de custos há muito tempo (Laureth, Wernke, Heberle \& Rufatto, 2018; Bezerra \& Silva, 2016; Colpo, Medeiros, Amorin \& Weiseet, 2015; Santos, Marion, \&, Kettle 2014; Marcousé, Surridge \& Gillespie, 2013; Martins, 2010; Bornia, 2009; Souza \& Diehl, 2009; Wernke, 2005).

Contudo, estudos especificamente voltados para a aplicação da Análise CVL em entidades privadas que atuam no ensino regular ou de idiomas raramente são 
publicados. A escassez de textos com essa abordagem pode ensejar dúvidas quanto aos benefícios que a aplicação dessa ferramenta gerencial pode propiciar ou acerca da necessidade de efetuar adaptações para implementá-la no âmbito desse tipo de empreendimento.

Nesse contexto é que surgiu a pergunta que se pretende responder nesta pesquisa: quais as informações gerenciais proporcionadas pela implementação da Análise CVL numa escola de idiomas? Para tanto, foi estipulado como objetivo de estudo identificar as informações gerenciais que podem ser obtidas por meio da Análise CVL nesse tipo de estabelecimento escolar.

Estudos como esse se justificam por, ao menos, dois motivos: o primeiro é pela importância econômica do segmento educacional privado, dado que é grande gerador de empregos e renda no país e o qualifica para merecer pesquisas na área de custos.

A segunda motivação está vinculada ao fato de que as publicações de contabilidade gerencial deveriam trazer contribuições com ênfase mais pragmática (Oyadomari, Cardoso, Mendonça Neto, Antunes, \& Aguiar, 2013; Lukka, 2010; Baldvinsdottir, Mitchell, \& Norreklit, 2010), como pretendido nesta pesquisa. Desse modo, poderá auxiliar os gerentes desses estabelecimentos de ensino a manusearem as ferramentas para gestão de custos com maior facilidade no sentido de obter informações importantes para subsidiar decisões cotidianas.

\section{REVISÃO DA LITERATURA}

A Análise Custo/Volume/Lucro (CVL), segundo ludícibus e Mello (2013), é uma das técnicas mais antigas e eficientes de análise de custos. Corroborando esse aspecto histórico, Barton, Shenkir e Hess (1995) mencionam que Wyatt Earp, um personagem lendário da época da colonização do "Velho Oeste" americano (que era ao mesmo tempo um xerife, caçador de búfalos e contador naquela região fronteiriça), já havia empregado este tipo de análise em três anos de sua atividade de caça. 
Os referidos autores ainda citam que ele mediu o custo total exigido em uma época de caça, previu o número de animais que poderia abater e calculou as receitas esperadas com a venda de peles e carnes. Além disso, avaliou os métodos de caça de outros caçadores e pensou em maneiras de melhorar a eficiência de sua própria caça. Destarte, embora tenha matado menos búfalos do que os demais, seus baixos custos operacionais e a sua forma inovadora de caçar the renderam lucros estáveis e riscos menores.

Quanto à utilização da Análise CVL como ferramenta gerencial, esta pode ser considerada um modelo que se difundiu no estudo comparativo da relação de uma empresa e seu ambiente e que proporciona diversos informes úteis aos administradores (Sulaiman, Ahmad, \& Alwi, 2004; D’Amato, Galvão, Villaça, Jorge, \& Tavares, 2012; Santos et al., 2014). Este artefato de contabilidade gerencial tem esse nome na medida em que abrange a relação que se estabelece entre o volume de produção (quantidade produzida ou vendida), o custo total dessa produção e o lucro respectivo (Hansen \& Mowen, 2001; Maher, 2001; Souza, Schnorr, \& Ferreira, 2011; Fonseca, 2012).

Quanto aos seus integrantes, aqueles de utilização cotidiana mais relevante são os conceitos de "margem de contribuição", "ponto de equilíbrio" e "margem de segurança" (Wernke, 2014).

Sobre a margem de contribuição, Souza e Rocha (2010) conceituam-na como o excesso do preço de venda líquido em relação aos custos e despesas variáveis, destinando-se a amortizar os custos e despesas fixas e a formar o lucro da empresa. Ressaltam que essa definição se aplica a cada produto ou família de produtos, às unidades de negócio e à empresa toda.

A mensuração da margem de contribuição é relativamente simples, pois visa identificar o que sobrou da receita de vendas depois de deduzidos os custos e as despesas variáveis de fabricação. $O$ valor resultante contribuirá para a cobertura dos custos fixos e para a formação do lucro. Portanto, teoricamente, os produtos que gerarem as maiores margens de contribuição são os que propiciam um lucro maior (Bartz, Fanfa, Kappel, \& Zonatto, 2009). 
No que concerne ao cálculo da margem de contribuição, Martins e Rocha (2010) defendem que da receita bruta sejam deduzidos os impostos para se obter a receita líquida e que deste valor devem ser descontados os custos e despesas variáveis para mensurar a margem de contribuição de cada produto.

Em relação ao ponto de equilíbrio, Zdanowicz (2012) destaca que equivale ao nível operacional onde o lucro do período é igual a zero. Assim, nesse volume de vendas, a empresa consegue cobrir todos os custos variáveis das unidades produzidas e vendidas, recuperando integralmente os seus custos fixos. No que tange ao cálculo do ponto de equilíbrio, Assaf Neto e Lima (2009) aduzem que este pode ser realizado utilizando a seguinte equação: [ $p \times q-C F-C V u \times q$ ], onde "p" é o preço de venda; "q" é a quantidade vendida; "CF" representa o valor dos custos fixos; "CVu" equivale ao custo variável por unidade e "x" é o sinal de multiplicação.

Em relação às possibilidades de cálculo do ponto de equilíbrio, Souza e Diehl (2009) citam que, dependendo da necessidade de informação, o gestor pode determinar o ponto de equilíbrio contábil (volume de vendas para obter resultado nulo), o econômico (para conseguir uma remuneração pelo investimento realizado) e o financeiro (para apenas cobrir os desembolsos de caixa).

Porém, as modalidades mencionadas são aplicáveis a apenas um produto. Como a maior parte das empresas comercializa vários produtos concomitantemente, o uso dessas fórmulas é restrito a poucas situações. Então, para Wernke (2010), no caso daquelas entidades que comercializam mais de um produto, deve-se calcular o ponto de equilíbrio mix, sendo que, para essas empresas, a principal dificuldade encontrada no cálculo do ponto de equilíbrio é a diversidade de produtos comercializados e as diferentes margens de contribuição destes.

Nesse contexto, para calcular o ponto de equilíbrio (em unidades) para vários produtos ao mesmo tempo, deve ser utilizada a fórmula do ponto de equilíbrio mix, exemplificada numericamente por Assaf Neto e Lima (2009). Ou seja, considere-se o caso de um posto de combustíveis cujos custos fixos mensais foram de $R \$ 4.000$, que o volume total de venda dos produtos no período foi de 8.500 litros, sendo que 2.500 
Gestão de Custos em Escola de Idiomas: Estudo de Caso com aplicação da Análise Custo/Volume/Lucro

Rodney Wernke, Lucas dos Santos Faccenda, Ivone Junges

litros de Gasolina (29,41\%), 2.000 litros de Diesel (23,53\%) e 4.000 litros de Álcool $(47,06 \%)$, e que a margem de contribuição total dos produtos no mesmo período foi de $\mathrm{R} \$ 5.700$.

Nessa realidade, ao utilizar a fórmula do PE Mix (unidades), chega-se ao valor de $5.964,91$ litros $[R \$ 4.000,00 /(R \$ 5.700,00 / 2.500$ litros)]. Para distribuir esse volume entre os três tipos de produtos comercializados, basta aplicar o percentual da quantidade vendida dos mesmos. Assim, o ponto de equilíbrio mix da Gasolina é de $1.754,39$ litros $(29,41 \%)$, do Diesel é de $1.403,51$ litros $(23,53 \%)$ e do Álcool é de $R \$$ $2.807,02(47,06 \%)$.

Em relação ao conceito de Margem de Segurança, Souza (2011) relata que esta representa a quantidade de produtos que é vendida acima ou abaixo do ponto de equilíbrio. Desse modo, quanto mais positiva essa margem, maior será a certeza de que a empresa não incorrerá em prejuízos e maior será a parcela do faturamento destinada a gerar lucro.

Acerca disso, Silva e Lins (2017) argumentam que a Margem de Segurança é o intervalo existente entre o volume de unidades vendido e aquele relativo ao ponto de equilíbrio. Então, supondo que determinada empresa venda 100 unidades e que seu ponto de equilíbrio seja de 80 unidades, consequentemente a sua margem de segurança será de 20 unidades.

\subsection{Benefícios e limitações associadas à Análise CVL}

Como toda ferramenta gerencial, a Análise Custo/Volume/Lucro possui pontos positivos e negativos.

A respeito dos benefícios proporcionados, diversos autores (Santos, 2005; Bornia, 2009; Souza \& Diehl, 2009; Yuan, 2009; Kisakürek, Kiliç, \& Yilmaz, 2011; Souza et al., 2011; Bonacim, Nardi, Silva, Cruz Júnior \& Bonizio, 2013; Etges, Calegari, Rhoden, \& Cortimiglia, 2016) citam aspectos relacionados com a mensuração da lucratividade de produtos, mercadorias ou serviços; cálculo do nível de equilíbrio das operações; auxílio para a administração decidir quais produtos devem ser priorizados 
Gestão de Custos em Escola de Idiomas: Estudo de Caso com aplicação da Análise Custo/Volume/Lucro

Rodney Wernke, Lucas dos Santos Faccenda, Ivone Junges

ou abandonados; avaliação de alternativas a respeito de reduções de preços, descontos especiais, campanhas publicitárias e uso de prêmios para aumentar o volume de vendas; ajuda os gerentes a entenderem a relação entre custos, volume, preços e lucros, levando a decisões mais sábias sobre preços; viabilidade econômica de projetos; elaboração de orçamentos e análise do efeito de custos sobre lucros.

Em sentido contrário, Garrison e Noreen (2001), Hansen e Mowen (2001), Bruni e Famá (2003), Dalmonech, Martinez, Viana e Ferreira (2003), Gitman (2004), Oliveira, Moura e Chaves (2008), Yuan (2009), Busan e Dina (2009), Martins (2010), Souza, Schnorr e Ferreira (2011), Bonacim et al., (2013) e Wernke (2014) elencaram como limitações atribuíveis à Análise CVL os seguintes aspectos: requer a linearidade de custos variáveis e receitas; suposição de produção igual a vendas; classificação dos custos semivariáveis; confronto entre despesas e receitas; natureza de curto prazo; considera custos e receitas em função das unidades produzidas; desconsideração do valor do dinheiro no tempo; suposição de perda zero; assume estrutura de capital 100\% próprio; supõe receita única; aplicação para um único produto, e as situações de riscos e incertezas não são consideradas.

\subsection{Estudos correlatos}

Quanto a pesquisas assemelhadas, no que concerne à gestão de custos na área de educação (mas, sem abordar especificamente a Análise CVL), é interessante mencionar os seguintes estudos:

a) Implementação do Activity-based Costing em escola de educação infantil (Cunha, Haussmann, \& Grieshaber, 2009);

b) Comparativo do custo por aluno de universidades de vários países efetuado por Soares, Mazon e Soares (2011);

c) Crozatti, Silveira, Pereira e Ferreira (2012) apresentaram modelo de mensuração e informação do custo e do resultado econômico de uma escola de Ensino Fundamental; 
Gestão de Custos em Escola de Idiomas: Estudo de Caso com aplicação da Análise Custo/Volume/Lucro

Rodney Wernke, Lucas dos Santos Faccenda, Ivone Junges

d) O estudo de Sant'Anna, Piacentini, Simões, Abreu e Kosztrzepa (2013) visou testar a adequação do $A B C$ na gestão dos gastos indiretos do SENAI, na unidade de Gravataí (RS);

e) Gonçalves, Cruz, Morais, Meirelles, Barbosa Junior e Peixoto (2014) compararam os métodos de custeio Absorção, Variável e ABC no âmbito de uma escola da cidade de Remígio (PB);

f) A pesquisa de Heusi, Moraes, Raupp e Beuren (2015) versou sobre a determinação do valor do custo por vaga e matrícula de universidade pública;

g) Levantamento feito por Lima e Cunha (2016) acerca da visão dos gestores de custos de quatro instituições de ensino superior sediadas em Minas Gerais;

h) Lopes, Flor, Lima, Vieira e Baccaro (2017) analisaram se as escolas de Santa Terezinha de Itaipu (PR) que possuem o maior custo por aluno são aquelas que ostentam o melhor desempenho no Índice de Desenvolvimento da Educação Básica (IDEB).

Quanto ao foco mais estrito do estudo, é possível encontrar na literatura diversas pesquisas que tratam da Análise CVL em empresas industriais, comerciais e prestadoras de serviços. Contudo, no âmbito das entidades que atuam no segmento educacional, as publicações sobre esse tema são mais escassas.

Nessa direção, pesquisas on-line realizadas em novembro de 2017, no Portal de Periódicos Capes e sites de eventos da área de custos (ENEGEP, SIMPEP e Congresso Brasileiro de Custos), indicaram alguns relatos que se aproximaram do foco ora priorizado, cujos principais aspectos são comentados na sequência.

Durieux, Beuren, Sousa e Raupp (2003) apresentaram proposta de sistema de custos para uma escola franqueada de idiomas, ou seja, apenas sugeriram um modelo de planilha de custos que evidenciaria o resultado das turmas por meio da margem de contribuição, sendo que esta seria obtida pela dedução dos custos (referentes ao pessoal, royalties etc.) e despesas variáveis da receita das vendas realizadas. Em seguida, da margem de contribuição total auferida pela empresa, seriam descontados os custos/despesas fixos para apurar o resultado mensal da escola. Entretanto, no texto 
não foram utilizados valores numéricos e evidenciaram, nas conclusões, que não se tratava de uma aplicação prática efetiva, ficando apenas no campo da proposição de uma ferramenta para tal contexto. Ainda, limitaram-se a sugerir o uso da margem de contribuição, sem adentrar nos demais conceitos da Análise CVL.

Silva, Benedicto e Salazar (2005) defendem que a Teoria das Restrições (Theory of Constraints - TOC) proposta por Goldratt (1991), que trataram equivocadamente como um "método de custeio", seria a mais adequada ao contexto de uma escola de idiomas que os métodos Absorção, Variável e Custeio Baseado em Atividades ( $A B C$ ). Apresentaram exemplos numéricos destas quatro concepções e concluíram que a Teoria das Restrições seria a metodologia que mais informações úteis poderia proporcionar ao gestor do empreendimento com base no fato de que esta levaria em conta o fator limitativo existente (o "tempo útil das salas de aula").

Contudo, no caso do cálculo referente à TOC, utilizaram um procedimento que nada mais é do que a margem de contribuição por fator restritivo, que há muito vem sendo mencionada na literatura de custos (ludícibus \& Mello, 2013; Martins, 2010; Horngren, Foster, Datar, Rajan, \& Ittner, 2009). Além disso, não exploraram as demais possibilidades da Análise CVL, visto que não fizeram os cálculos relacionados com ponto de equilíbrio e margem de segurança, por exemplo.

Baesso (2008) descreveu o sistema de custeio utilizado por uma pequena empresa do setor de ensino de idiomas. Constatou que era empregado o custeio variável, acompanhado da medição da margem de contribuição, e concluiu que este era adequado para a tomada de decisões e para a análise do desempenho de curto prazo da entidade pesquisada.

Souza, Schnorr e Ferreira (2011) objetivaram analisar a estrutura de custos de uma escola privada de Educação Infantil e Ensino Fundamental. Por meio do custeio variável, concluíram que é possível conhecer o valor da margem de contribuição e do ponto de equilíbrio naquela realidade empresarial.

Wernke, Farias Júnior, Lembeck e Mendes (2011) relataram estudo de caso sobre aplicação da Análise Custo/Volume/Lucro (CVL) no contexto de escola de 
educação infantil (crianças de zero a seis anos). Tal pesquisa demonstrou que a utilização da Análise CVL permitiu aos proprietários do empreendimento conhecer a rentabilidade de cada turma individualmente; apurar quais turmas contribuem mais para o resultado do período; determinar o ponto de equilíbrio das operações da escola e por turma; identificar a margem de segurança do negócio; elaborar uma demonstração do resultado em formato gerencial e mensurar a lucratividade do período, evidenciando a participação percentual de cada fator no resultado mensal.

Como visto, não há relatos de aplicação detalhada da Análise CVL no contexto de uma escola de idiomas de pequeno porte, o que pode ser considerado uma pequena lacuna de pesquisa para a qual se pretende contribuir para minimizá-la, conforme descrito em detalhes nas próximas seções.

\section{METODOLOGIA}

No âmbito da forma de abordagem do problema, o estudo pode ser classificado como "qualitativo", de vez que é assim que Richardson (1999) denomina as pesquisas que objetivam descrever a complexidade de determinada questão, analisar a interação de certas variáveis, compreender e classificar processos dinâmicos vividos por grupos sociais.

Acerca da tipologia quanto aos objetivos, este estudo pode ser classificado como "descritivo", porque a referida modalidade se preocupa em observar os fatos, registrálos, analisá-los, classificá-los e interpretá-los, sem que o pesquisador intervenha (Rauen, 2015; Andrade, 2002).

Em relação aos procedimentos adotados, caracteriza-se como estudo de caso, pois se concentra numa específica escola de idiomas, e suas conclusões limitam-se ao contexto desse objeto de estudo (Yin, 2005). Além disso, a escolha por este procedimento deu-se pelo motivo de que permitiria um aprofundamento a respeito desse tipo de empresa, bem como facilitaria o conhecimento das possíveis dificuldades que a adaptação da ferramenta gerencial escolhida teria nesse contexto empresarial. 
Gestão de Custos em Escola de Idiomas: Estudo de Caso com aplicação da Análise Custo/Volume/Lucro

Rodney Wernke, Lucas dos Santos Faccenda, Ivone Junges

A pesquisa foi realizada em março de 2017, numa escola de idiomas sediada em cidade do sul de Santa Catarina, que contava, à época do estudo, com 22 professores e 10 funcionários na parte administrativa.

Por opção dos sócios da empresa, omite-se neste relato a razão social e o valor do faturamento da entidade, que trabalha sob a bandeira de uma rede de franquias que atua em vários estados brasileiros. Nessa direção, o contrato entre essas partes exige somente a aquisição do material escolar a ser repassado aos alunos matriculados, ficando a administração inteiramente a cargo dos empreendedores/franqueados.

Quanto à escolha da empresa como objeto deste estudo, esta ocorreu em virtude da possibilidade de acessar os dados necessários, conforme disponibilizado pelos sócios do empreendimento. Destarte, os resultados oriundos não podem ser generalizados, devendo ficar circunscritos aos limites do caso ora relatado.

No que concerne aos procedimentos relacionados à coleta de dados, nos estudos de caso é possível combinar métodos como entrevistas, pesquisas em arquivos, questionários, relatos verbais e observações, sendo que as evidências podem ser qualitativas e quantitativas (Marques, Camacho, \& Alcantara, 2015).

Portanto, nesta pesquisa, foram empregadas as técnicas de conversas informais (entrevistas não estruturadas) com o gestor da escola e com o contador, observação in loco sobre as atividades da escola, bem como foi efetuada análise documental nos controles internos (relatórios/planilhas de alunos por turma, contratos de prestação de serviços e outros) e na contabilidade da empresa (faturamento, tributação incidente e valor das mensalidades por turma), com a intenção de conhecer a situação vigente quanto aos dados necessários para efetuar o estudo pretendido.

Quanto à duração das entrevistas não estruturadas (realizadas por intermédio de conversas informais), como estas ocorreram ao longo do período de pesquisa à medida da necessidade dos pesquisadores, não foram registradas formalmente, e a duração total estimada foi de cerca de dez horas. Convém salientar, ainda, que não foi adotado um roteiro para essas entrevistas para evitar que alguma informação mais relevante 
deixasse de ser obtida, pois os gestores se prontificaram a esclarecer dúvidas e fornecer os dados necessários sempre que fossem solicitados.

$\mathrm{Na}$ sequência, iniciou-se a coleta dos dados requeridos para execução do trabalho nos controles internos existentes (elaborados em planilha Excel e atualizados pela área administrativa da organização), além de outros informes mais específicos que foram obtidos junto ao gerente e ao contador da firma.

Adicionalmente, para avaliar o rigor metodológico deste estudo de caso quanto aos aspectos formais, foram utilizados os critérios recomendados por Marques et al. (2015) quanto ao:

a) Objeto de estudo: os pesquisadores procuraram entender o fenômeno em tela no seu contexto real; foram explicadas as razões de adotar esta estratégia de pesquisa; verifica-se a existência de ligação entre o fenômeno em questão e o contexto pesquisado; a questão de estudo está claramente formulada e o tipo de estudo é descritivo.

b) Coleta de dados: há diversas formas de evidenciação (entrevistas com gestor e contador, relatórios de controles internos e registros contábeis) que permitem triangular os dados considerados na pesquisa; é possível comprovar a fidedignidade dos dados utilizados pelos controles internos e contábeis; medidas operacionais (como margem de contribuição por turma de alunos e ponto de equilíbrio, entre outras) foram elaboradas para validar o constructo estudado; são comentadas as formas como os dados foram obtidos e há a possibilidade de replicar a coleta de dados em outro contexto assemelhado.

c) Análise dos dados: os resultados decorrentes do estudo são oriundos dos dados coligidos, e foi empregada teoria anterior para embasar as análises efetuadas.

d) Resultados oriundos: foram comentadas as contribuições em relação a estudos precedentes, bem como foram citados alguns pontos que ainda precisam de continuação nesse tipo de investigação. 
Gestão de Custos em Escola de Idiomas: Estudo de Caso com aplicação da Análise Custo/Volume/Lucro Rodney Wernke, Lucas dos Santos Faccenda, Ivone Junges

\section{APRESENTAÇÃO E DISCUSSÃO DOS RESULTADOS}

Inicialmente, foi realizado um levantamento de dados de todas as 87 turmas em andamento no mês da pesquisa, como está resumidamente apresentado na Tabela 1.

Porém, cabe esclarecer que, nesta e nas próximas tabelas, constam detalhes de somente algumas das 87 turmas abrangidas para adequação às restrições da revista.

Tabela 1

Dados sobre as turmas

\begin{tabular}{c|l|l|c|c|c}
\hline & \multicolumn{1}{|c|}{ Turma } & \multicolumn{1}{|c|}{ Programa - Estágio } & Mensalidade & Material \\
\cline { 4 - 6 } No. ord. & \multicolumn{1}{|c|}{ Alunos } & Por aluno R\$ & Por aluno R\$ \\
\hline 1 & Básico 1 THU 10:15/11:15 & Outras Línguas: Italiano - Básico 1 - NPI & 2 & 265,72 & 68,00 \\
\hline 2 & Básico 1 WED 20:00/22:00 & Outras Línguas: Italiano - Básico 1 - NPI & 2 & 260,05 & 68,00 \\
\hline 3 & Básico 2 THU 09:15/10:15 & Outras Línguas: Italiano - Básico 2 - NPI & 1 & 285,69 & 35,33 \\
\hline 4 & Básico 2 TUE 19:15/20:15 & Outras Línguas: Italiano - Básico 2 - NPI & 1 & 233,74 & 35,33 \\
\hline$\ldots$ & Outros & Outros & - & - & - \\
\hline 87 & YTEEN 3 TT 13:45/14:45 & YTEEN - YTEEN 3 & 6 & 316,53 & 68,00 \\
\hline
\end{tabular}

Nota. Fonte: Elaborada pelos autores

Em seguida, para cada uma dessas turmas, foram apurados dados na planilha de controle interno, utilizada pelo proprietário da escola sobre o número de alunos, o valor das mensalidades cobradas e o custo unitário de aquisição do material disponibilizado aos alunos.

Com isso, foi possível calcular a margem de contribuição por aluno, como exposto na próxima seção.

\subsection{Margem de contribuição por aluno em cada turma}

O conceito de margem de contribuição mais difundido afirma que do preço de venda devem ser descontados os custos/despesas variáveis. No caso da escola de idiomas em tela, o procedimento de cálculo foi adaptado a partir dessa concepção, como exposto na Tabela 2. 
Gestão de Custos em Escola de Idiomas: Estudo de Caso com aplicação da Análise Custo/Volume/Lucro Rodney Wernke, Lucas dos Santos Faccenda, Ivone Junges

Tabela 2

Margem de contribuição unitária, por aluno, em cada turma

\begin{tabular}{c|c|c|c|c|c|c}
\hline & & Mensalidade & Simples & Material & MC unit. & MC unit. \\
\cline { 3 - 7 } Turma & Alunos & p/aluno (R\$) & p/aluno (R\$) & p/aluno (R\$) & p/aluno (R\$) & p/aluno (\%) \\
\hline Básico 1 THU 10:15/11:15 & 2 & 265,72 & 31,49 & 68,00 & 166,23 & $62,56 \%$ \\
\hline Básico 1 WED 20:00/22:00 & 2 & 260,05 & 30,82 & 68,00 & 161,23 & $62,00 \%$ \\
\hline Básico 2 THU 09:15/10:15 & 1 & 285,69 & 33,85 & 35,33 & 216,51 & $75,78 \%$ \\
\hline Básico 2 TUE 19:15/20:15 & 1 & 233,74 & 27,70 & 35,33 & 170,71 & $73,03 \%$ \\
\hline Outros... & - & - & - & - & - & - \\
\hline YTEEN 3 TT 13:45/14:45 & 6 & 316,53 & 37,51 & 68,00 & 211,02 & $66,67 \%$ \\
\hline
\end{tabular}

Nota. Fonte: elaborada pelos autores

Nesse sentido, para exemplificar o cálculo, considerem-se os dados citados para a última turma mencionada na Tabela 2 (“YTEEN 3 TT 13:45/14:45"):

a) Valor da mensalidade por aluno: $\mathrm{R} \$ 316,53$ (conforme contrato de prestação de serviços);

b) Tributos incidentes sobre as vendas: $\mathrm{R} \$ 37,51$ (com base na alíquota informada pelo contador da empresa);

c) Custo de compra do material escolar disponibilizado ao aluno: $\mathrm{R} \$ 68,00$ (valor obtido na nota fiscal do fornecedor/franquia);

d) Margem de contribuição unitária (em $R \$$ ) por aluno da turma: $R \$ 211,02(R \$$ $316,53-R \$ 37,51-R \$ 68,00)$;

e) Margem de contribuição unitária (em \%) por aluno: 66,67\% (R\$211,02 / $R \$$ $316,53 \times 100)$.

\subsection{Margem de contribuição total por turma}

Depois de conhecer a contribuição por aluno de cada turma, foi apurada a margem de contribuição total destas, como apresentado na Tabela 3. 
Gestão de Custos em Escola de Idiomas: Estudo de Caso com aplicação da Análise Custo/Volume/Lucro

Rodney Wernke, Lucas dos Santos Faccenda, Ivone Junges

Tabela 3

Margem de contribuição total das turmas

\begin{tabular}{|l|c|c|c|c|c|}
\hline \multirow{2}{*}{ Turma } & Mensalidades & Simples & Material & Marg. Contrib. & Marg. Contrib. \\
\cline { 2 - 6 } & Total mês (R\$) & Total mês (R\$) & Total mês (R\$) & Total mês (R\$) & $\%$ do total \\
\hline Básico 1 THU 10:15/11:15 & 531,44 & 62,98 & 136,00 & 332,46 & $0,47 \%$ \\
\hline Básico 1 WED 20:00/22:00 & 520,10 & 61,63 & 136,00 & 322,47 & $0,45 \%$ \\
\hline Básico 2 THU 09:15/10:15 & 285,69 & 33,85 & 35,33 & 216,51 & $0,30 \%$ \\
\hline Básico 2 TUE 19:15/20:15 & 233,74 & 27,70 & 35,33 & 170,71 & $0,24 \%$ \\
\hline Outros & - & - & - & - & - \\
\hline YTEEN 3 TT 13:45/14:45 & $1.899,18$ & 225,05 & 408,00 & $1.266,13$ & $1,78 \%$ \\
\hline Totais & $120.414,27$ & $14.269,09$ & $34.831,03$ & $71.314,15$ & $100,00 \%$ \\
\hline
\end{tabular}

Nota. Fonte: elaborado pelos autores

No caso da Tabela 3, foram considerados os valores totais de mensalidades, tributos incidentes e material escolar disponibilizado aos alunos em cada turma no mês da pesquisa. Para tanto, bastou multiplicar os valores unitários (vide Tabela 2) pelo número de alunos das classes. Como visto, a margem de contribuição total do mês alcançou $R \$ 71.314,15$ e foi possível apurar também a participação percentual de cada turma no montante do mês neste parâmetro.

A avaliação do desempenho por turma pode ser aprimorada com a comparação da participação destas no faturamento do período e na margem de contribuição total respectiva, como delineado no Gráfico 1. 
Gestão de Custos em Escola de Idiomas: Estudo de Caso com aplicação da Análise Custo/Volume/Lucro

Rodney Wernke, Lucas dos Santos Faccenda, Ivone Junges

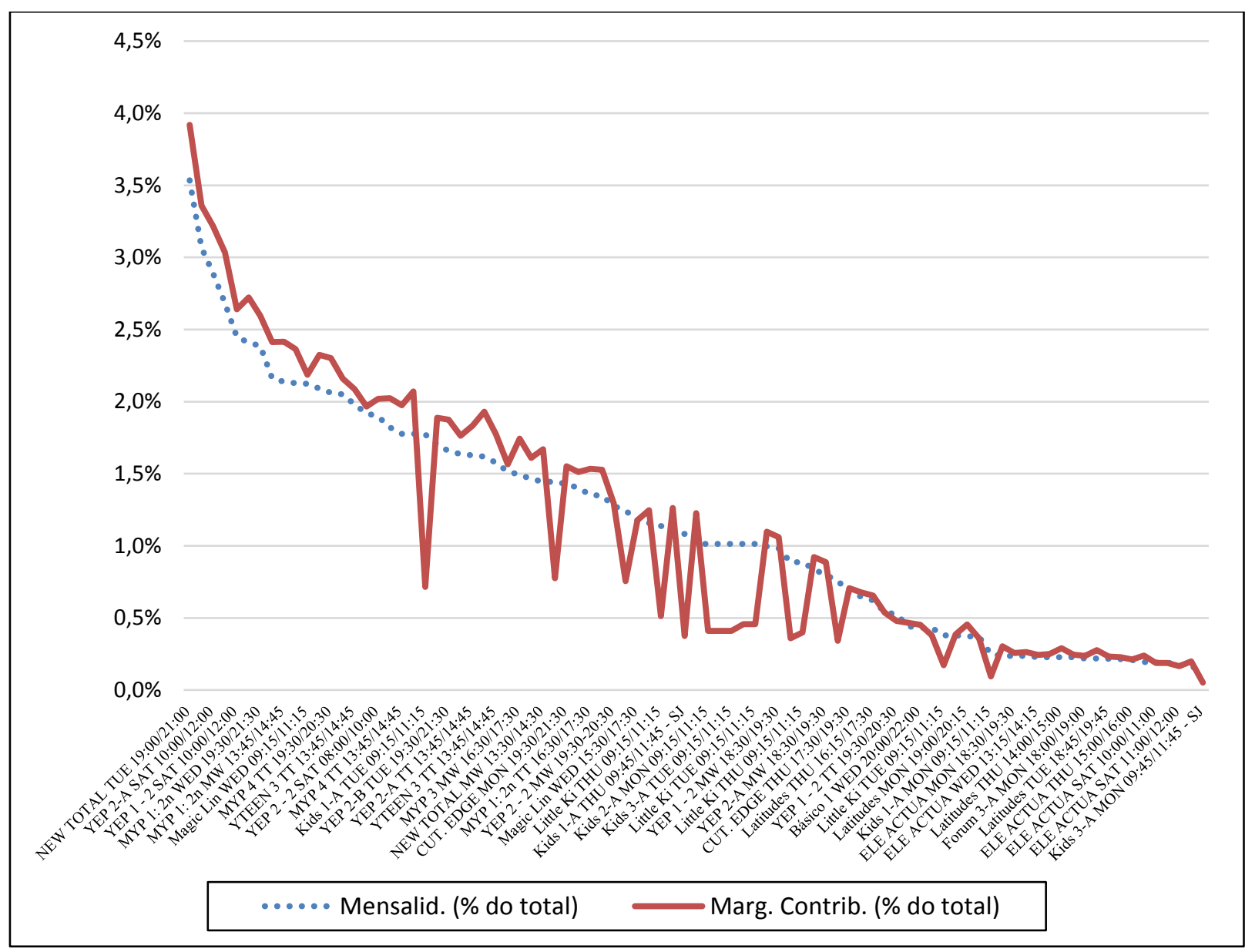

Gráfico 1. Participação percentual das turmas no faturamento e na margem de contribuição total Fonte: elaborado pelos autores.

Ou seja, foi identificado que há turmas que possuem participação percentual maior no faturamento total (linha pontilhada) do que têm na margem de contribuição total (linha contínua) e vice-versa. Quanto maior a participação na margem de contribuição, mais relevante pode ser considerada a turma.

\subsection{Determinação do ponto de equilíbrio por turma}

Para conhecer o ponto de equilíbrio da escola e das turmas individualmente, foram percorridas algumas etapas, como descrito em detalhes a seguir. 
Gestão de Custos em Escola de Idiomas: Estudo de Caso com aplicação da Análise Custo/Volume/Lucro

Rodney Wernke, Lucas dos Santos Faccenda, Ivone Junges

O primeiro passo consistiu em levantar todos os gastos fixos a partir dos controles internos da empresa, onde foram apurados os seguintes valores:

a) despesas administrativas: $\mathrm{R} \$ 44.589,61$ (gastos com depreciação predial, salários de funcionários, impostos sobre propriedade, depreciação de equipamentos, água, luz, telefone, internet e outros);

b) despesas operacionais: $R \$ 19.062,92$ (que abrangem, basicamente, contador, assistência técnica a computadores e eletrônicos, pro-labore dos gestores da organização e encargos associados);

c) despesas financeiras: $R \$ 3.180,12$ (que se referem a itens como juros e tarifas bancárias).

Em seguida, foram reunidos os demais dados para calcular o ponto de equilíbrio, ou seja, a margem de contribuição total ( $R \$ 71.314,15$ que já haviam sido calculados em Tabela anterior e a quantidade de mensalidades vendidas no período do estudo, que foi de 474 mensalidades). Referidos valores fundamentaram a aplicação da fórmula do ponto de equilíbrio mix nos moldes do exposto na Tabela 4.

Tabela 4

Ponto de equilíbrio mix - Etapa 1 (total da escola)

\begin{tabular}{l|c}
\hline \multicolumn{1}{c|}{$\quad$ Itens } & Valores \\
\hline 1) Despesas administrativas $\mathrm{R} \$$ & $44.589,61$ \\
\hline 2) Despesas operacionais $\mathrm{R} \$$ & $19.062,92$ \\
\hline 3) Despesas financeiras $\mathrm{R} \$$ & $3.180,12$ \\
\hline $\mathrm{a}=1+2+3)$ Gastos Fixos Mensais da Empresa $\mathrm{R} \$$ & $66.832,65$ \\
\hline b) Margem de Contribuição Total $\mathrm{R} \$$ & $71.314,15$ \\
\hline c) $\mathrm{Quantidade}$ vendida de mensalidades & 474 \\
\hline $\mathrm{d}=\mathrm{a} /(\mathrm{b} / \mathrm{c})$ ] Ponto de Equilíbrio em unidades mix (mensalidades) & 444,21 \\
\hline
\end{tabular}

Nota. Fonte: elaborada pelos autores

Então, ao dividir o gasto fixo mensal da escola $(\mathrm{R} \$ 66.832,65)$ pelo resultado da divisão do valor da margem de contribuição total $(R \$ 71.314,15)$ pela quantidade vendida de mensalidades (474), apurou-se que a entidade precisava vender 444,21 
Gestão de Custos em Escola de Idiomas: Estudo de Caso com aplicação da Análise Custo/Volume/Lucro

Rodney Wernke, Lucas dos Santos Faccenda, Ivone Junges

mensalidades para alcançar o ponto de equilíbrio contábil (que equivale a não ter lucro nem incorrer em prejuízo).

Como essa quantidade referia-se ao total da empresa, foi necessário efetuar um segundo cálculo para individualizar o ponto de equilíbrio por turma, como demonstrado na Tabela 5.

Tabela 5

Ponto de equilíbrio mix em mensalidades - Etapa 2

\begin{tabular}{l|c|c|c|c|c}
\hline \multirow{2}{*}{ Turma } & Quantidade & $\%$ do & PE Mix em & Mensalidade & PE Mix em \\
\cline { 2 - 6 } & de mensalid. & total & Mensalid. & por aluno (R\$) & Valor R\$ \\
\hline Básico 1 THU 10:15/11:15 & 2 & $0,42 \%$ & 1,87 & 265,72 & 498,04 \\
\hline Básico 1 WED 20:00/22:00 & 2 & $0,42 \%$ & 1,87 & 260,05 & 487,42 \\
\hline Básico 2 THU 09:15/10:15 & 1 & $0,21 \%$ & 0,94 & 285,69 & 267,74 \\
\hline Básico 2 TUE 19:15/20:15 & 1 & $0,21 \%$ & 0,94 & 233,74 & 219,05 \\
\hline Outros & - & - & - & - & - \\
\hline YTEEN 3 TT 13:45/14:45 & 6 & $1,27 \%$ & 5,62 & 316,53 & $1.779,83$ \\
\hline Totais & 474 & $100,00 \%$ & 444,21 & - & $112.847,24$ \\
\hline
\end{tabular}

Nota. Fonte: elaborada pelos autores

Ou seja, inicialmente foi apurado o percentual de cada turma no número total de mensalidades (ou alunos). Em seguida, esse percentual foi aplicado sobre o valor total do ponto de equilíbrio (444,21 mensalidades) para determinar o volume necessário de alunos que cada turma deveria ter para que a escola atingisse o nível de equilíbrio.

Posteriormente, foi multiplicado esse ponto de equilíbrio por turmas pelo respectivo preço da mensalidade. Com isso, foi calculado o ponto de equilíbrio em valor monetário $(R \$)$ de cada turma no período, cujo total da escola chegou a $R \$ 112.847,24$. Destarte, a empresa precisaria faturar esse montante para ter resultado nulo no mês pesquisado.

Uma forma de comprovar a exatidão do cálculo do ponto de equilíbrio é multiplicar o volume determinado para cada turma pela margem de contribuição unitária respectiva. Ao se fazer essa multiplicação, constatou-se que no volume de equilíbrio a 
Gestão de Custos em Escola de Idiomas: Estudo de Caso com aplicação da Análise Custo/Volume/Lucro

Rodney Wernke, Lucas dos Santos Faccenda, Ivone Junges

empresa conseguiria margem de contribuição total de $R \$ 66.832,65$, que equivale ao gasto fixo mensal. Assim, se vendesse mais que esse volume de 444,21 mensalidades, passaria a lucrar; se vendesse menos, teria prejuízo.

\subsection{Margem de segurança}

O outro conceito importante relacionado à Análise CVL é o da Margem de Segurança, sendo que, no contexto da pesquisa, esse parâmetro foi mensurado como descrito na Tabela 6.

Tabela 6

Margem de segurança em unidades e valor (R\$)

\begin{tabular}{l|c|c|c|c|c}
\hline \multirow{2}{*}{ Turma } & Vendas & $\begin{array}{c}\text { Ponto de } \\
\text { Equilíbrio Mix }\end{array}$ & $\begin{array}{c}\text { Margem de } \\
\text { Segurança }\end{array}$ & $\begin{array}{c}\text { Preço } \\
\text { de Venda }\end{array}$ & $\begin{array}{c}\text { Margem de } \\
\text { Segurança }\end{array}$ \\
\cline { 2 - 6 } & em Mensalid. & em Mensalid. & em Mensalid. & unitário R\$ & em valor (R\$) \\
\hline Básico 1 THU 10:15/11:15 & 2 & 1,87 & 0,13 & 265,72 & 33,40 \\
\hline Básico 1 WED 20:00/22:00 & 2 & 1,87 & 0,13 & 260,05 & 32,68 \\
\hline Básico 2 THU 09:15/10:15 & 1 & 0,94 & 0,06 & 285,69 & 17,95 \\
\hline Básico 2 TUE 19:15/20:15 & 1 & 0,94 & 0,06 & 233,74 & 14,69 \\
\hline Outros & - & - & - & - & - \\
\hline YTEEN 3 TT 13:45/14:45 & 6 & 5,62 & 0,38 & 316,53 & 119,35 \\
\hline Totais & 474 & 444,21 & 29,79 & $22.198,76$ & $7.567,03$ \\
\hline
\end{tabular}

Nota. Fonte: elaborada pelos autores

De início, foi apurada a margem de segurança em unidades (mensalidades, no caso). Para tanto, do ponto de equilíbrio de 474 mensalidades, foi descontado o volume de 444,21 mensalidades, gerando margem de segurança de 29,79 mensalidades. Com o mesmo procedimento, feito para cada turma, foi possível conhecer também as margens de segurança respectivas.

Em seguida, foi multiplicada a margem de segurança em mensalidades de cada turma pelo respectivo preço de venda unitário (em $\mathrm{R} \$$ ), o que evidenciou o valor da margem de segurança em valor monetário $(R \$)$ das turmas e o total da empresa $(R \$$ 
Gestão de Custos em Escola de Idiomas: Estudo de Caso com aplicação da Análise Custo/Volume/Lucro

Rodney Wernke, Lucas dos Santos Faccenda, Ivone Junges

$7.567,03)$. Com isso, assume-se que o faturamento da escola poderia cair até esse valor que a mesma ainda não entraria na faixa de prejuízo.

\subsection{Demonstração do resultado do período}

Outra informação importante propiciada por esta pesquisa relaciona-se à possiblidade de apurar o resultado do período com base nos dados anteriormente utilizados. No caso em questão, o resultado mensal da empresa está retratado na Tabela 7.

Tabela 7

Resultado do Período

\begin{tabular}{l|c|c}
\hline \multicolumn{1}{c|}{ Itens } & Valor $\mathbf{R} \$$ & $\%$ das Vendas \\
\hline (+) Vendas do período & $120.414,27$ & $100,00 \%$ \\
\hline (-) Tributos sobre vendas - Simples & $14.269,09$ & $11,85 \%$ \\
\hline (-) Material escolar & $34.831,03$ & $28,93 \%$ \\
\hline (=) Margem de contribuição total & $71.314,15$ & $59,22 \%$ \\
\hline (--) Despesas administrativas & $44.589,61$ & $37,03 \%$ \\
\hline (--) Despesas operacionais & $19.062,92$ & $15,83 \%$ \\
\hline (--) Despesas financeiras & $3.180,12$ & $2,64 \%$ \\
\hline (=) Resultado do período & $4.481,50$ & $3,72 \%$ \\
\hline
\end{tabular}

Nota. Fonte: elaborada pelos autores.

Como visto, da margem de contribuição foi descontado o valor das despesas fixas do empreendimento, onde se apurou que o lucro foi de $R \$ 4.481,50$ no período (acarretando taxa de lucratividade de 3,72\% sobre as vendas).

\subsection{Desempenho por grupos de turmas}

A última informação que se obteve da análise CVL realizada se refere ao desempenho por grupos de turmas, como exposto na Tabela 8. 
Gestão de Custos em Escola de Idiomas: Estudo de Caso com aplicação da Análise Custo/Volume/Lucro Rodney Wernke, Lucas dos Santos Faccenda, Ivone Junges

Tabela 8

Desempenho por grupos de turmas

\begin{tabular}{l|c|c|c|c}
\hline \multicolumn{1}{c|}{ Grupos de turmas } & Vendas R\$ & \% das Vendas & MC Total $\mathbf{R}$ & \% da MC Total \\
\hline Básico 1 e 2 & $1.570,97$ & $1,30 \%$ & $1.042,15$ & $1,46 \%$ \\
\hline Cut. Edge & $2.524,23$ & $2,10 \%$ & $1.610,14$ & $2,26 \%$ \\
\hline Ele Actua & $2.702,16$ & $2,24 \%$ & $1.630,32$ & $2,29 \%$ \\
\hline Forum 3-A & 264,02 & $0,22 \%$ & 168,07 & $0,24 \%$ \\
\hline Kids 1, 2 e 3 & $11.844,05$ & $9,84 \%$ & $3.103,28$ & $4,35 \%$ \\
\hline Latitudes & $3.656,88$ & $3,04 \%$ & $2.351,59$ & $3,30 \%$ \\
\hline Le Nouvel & 538,85 & $0,45 \%$ & 372,84 & $0,52 \%$ \\
\hline Little Ki & $6.765,21$ & $5,62 \%$ & $1.936,15$ & $2,71 \%$ \\
\hline Magic Lin & $13.569,47$ & $11,27 \%$ & $8.491,69$ & $11,91 \%$ \\
\hline MYP 1, 2, 3 e 4 & $24.116,75$ & $20,03 \%$ & $16.134,17$ & $22,62 \%$ \\
\hline New Total & $10.518,21$ & $8,74 \%$ & $7.016,91$ & $9,84 \%$ \\
\hline Nuevo Chi & 198,04 & $0,16 \%$ & 141,24 & $0,20 \%$ \\
\hline Raise & $1.219,92$ & $1,01 \%$ & 875,38 & $1,23 \%$ \\
\hline YEP 1 e 2 & $32.365,48$ & $26,88 \%$ & $20.934,55$ & $29,36 \%$ \\
\hline Yteen 1 e 3 & $8.560,03$ & $7,11 \%$ & $5.505,67$ & $7,72 \%$ \\
\hline Totais & $120.414,27$ & $100,00 \%$ & $71.314,15$ & $100,00 \%$ \\
\hline
\end{tabular}

Nota. Fonte: elaborada pelos autores

Os "grupos" de turmas abrangem as turmas com as mesmas características, mas cujas aulas são ministradas em horários/períodos diferentes.

Nesse sentido, percebe-se que o grupo "YEP 1 e 2" é, ao mesmo tempo, o de maior faturamento e o de maior margem de contribuição total. Na segunda posição, aparece o grupo "MYP 1, 2, 3 e 4" e, na terceira colocação, o grupo "Magic Lin". Esta análise pode servir para decidir sobre quais segmentos devem ser priorizados em campanhas promocionais, por exemplo, porque, quanto mais margem de contribuição um grupo de cursos proporcionar, mais interessante se tornará aos olhos dos administradores.

\subsection{Discussão dos resultados}

O estudo acerca da Análise CVL na escola de idiomas pesquisada trouxe 
informações úteis para a gestão do empreendimento, cujas mais relevantes são evidenciadas a seguir:

a) Margem de contribuição de cada turma: permite mensurar o resultado da prestação dos serviços destas e, com isso, o gestor poderá conhecer quais turmas são as mais lucrativas ou aquelas com menor capacidade de geração de caixa.

b) Ponto de equilíbrio em número de alunos e faturamento (em $\mathrm{R} \$$ ) por turma: o conhecimento dessas informações possibilita ao gerente identificar a quantidade mínima de alunos (ou de faturamento) por turma a partir da qual a empresa passa a lucrar. O mesmo procedimento de cálculo, com adaptação na fórmula utilizada, também pode deslindar o nível de vendas para atingir determinado lucro (o ponto de equilíbrio econômico).

c) Margem de segurança de cada turma: faculta aos gestores mensurar qual o montante de queda nas vendas (em $\mathrm{R} \$$ e em número de alunos) que a escola suportaria sem entrar na faixa de prejuízo.

d) Gastos fixos mensais da entidade: a Análise CVL possibilita fazer simulações de cenários acerca dos impactos no lucro do período, decorrentes da contratação ou dispensa de funcionários, de retiradas maiores de pro-labore e da elevação de despesas operacionais (entre outras possibilidades).

e) Apuração do resultado do período: mesmo sendo uma informação básica para qualquer administrador, os proprietários não sabiam como avaliar o resultado mensal do empreendimento de forma mais consistente a partir dos controles internos da entidade. Assim, a ferramenta disponibilizada permitiu conhecer essa informação, além de mostrar a participação dos itens em relação às vendas do período (análise vertical).

Quanto às limitações que podem ser associadas ao estudo realizado, além daquelas relativas à teoria que fundamenta a Análise CVL listadas anteriormente, é pertinente destacar dois pontos.

O primeiro relaciona-se com a produtividade dos ativos. Apesar de o resultado do 
período ter sido considerado adequado pelos proprietários da escola de idiomas, na avaliação relatada não foi medida a produtividade dos ativos, ou seja, se o lucro auferido era condizente com o valor dos ativos empregados no empreendimento. Por exemplo: supondo-se que o terreno e o prédio escolar fossem avaliados em $R \$$ $500.000,00$, o lucro de $R \$ 4.481,50$ (apurado na Tabela 7 ) representaria apenas $0,896 \%$ de retorno sobre esse montante de ativos.

O segundo aspecto refere-se ao custo de oportunidade, pois os recursos aplicados em ativos físicos da entidade (principalmente equipamentos, terreno e prédio) são expressivos, mas não foi considerado o custo do capital associável a esse montante aplicado na escola em tela.

Como descrito anteriormente, os estudos que mais se aproximaram do enfoque aplicado a esta pesquisa foram os de Durieux et al. (2003) e Wernke et al. (2011).

Enquanto que o primeiro apenas propôs a utilização da Análise CVL numa escola de idiomas (sem utilização de valores monetários), a segunda pesquisa aplicou essa análise em uma escola de Educação Infantil de forma assemelhada ao relatado acima, apurando informações gerenciais semelhantes. Contudo, tal estudo abrangeu apenas seis turmas, enquanto que nesta pesquisa foram consideradas as 87 (oitenta e sete) turmas em andamento no mês enfocado, o que contribui para uma maior robustez dos resultados oriundos.

\section{CONSIDERAÇÕES FINAIS}

A pesquisa visou responder questão de estudo relacionada às informações gerenciais oriundas da implementação da Análise CVL numa escola de idiomas. Nesse rumo, o objetivo do estudo consistiu em identificar as informações gerenciais que podem ser obtidas por meio da Análise CVL nesse tipo de entidade.

Assim, com fulcro no exposto nas seções precedentes, os autores entendem que a pergunta de pesquisa foi respondida adequadamente e o objetivo citado foi alcançado porque restou evidenciado que a Análise CVL tem a capacidade de proporcionar 
diversos informes úteis aos administradores dessa escola de idiomas. Nesse sentido, salienta-se que o cálculo dos integrantes dessa forma de análise foi realizado sem a necessidade de ajustes ou modificações significativas nas equações que tradicionalmente têm sido divulgadas na literatura pertinente.

Quanto aos resultados do estudo, é válido destacar a grande quantidade de informações gerenciais que a aplicação da Análise CVL possibilitou obter nesse contexto empresarial, sendo que os principais benefícios informativos foram: (I) a margem de contribuição unitária das mensalidades de cada turma, bem como a margem de contribuição total por turmas e grupos de turmas; (ii) o ponto de equilíbrio em mensalidades e valor por turma; (iii) a margem de segurança em número de mensalidades e em valor monetário de cada turma; e (iv) o demonstrativo de resultado do período, o que permitiu conhecer os fatores que compõem o lucro/prejuízo do mês, bem como a participação percentual de cada fator.

Portanto, o gestor dessa escola de idiomas passou a dispor de informações tecnicamente mais consistentes acerca do desempenho das turmas de alunos, dos grupos de turmas e da empresa que dirige.

Adicionalmente, considera-se que esta pesquisa pode contribuir de forma prática e também teórica. No âmbito teórico, entende-se que, ao evidenciar a aplicabilidade da Análise CVL nesse contexto empresarial, contribuiu ao mostrar que essa ferramenta da área de custos pode ser aplicada em estabelecimentos de ensino de idiomas, que se caracterizam por trabalharem com grande quantidade de turmas, mas com poucos alunos por turma. Com isso, considera-se que houve uma contribuição, mesmo que pequena, para preencher uma lacuna de estudo acerca dessa forma de análise gerencial.

Em relação ao aspecto prático, convém enaltecer que, ao se utilizar a Análise CVL nessa escola de idiomas, foi exemplificada uma aplicação efetiva que pode servir de auxílio para empresários e gerentes de escolas semelhantes implementarem-na em suas empresas e usufruírem dos benefícios decorrentes. Com isso, corrobora-se o posicionamento de Oyadomari et al. (2013), Lukka (2010) e Baldvinsdottir et al. (2010) 
quanto à importância de validar conceitos da contabilidade gerencial em experimentos reais.

Entretanto, é pertinente mencionar a existência de limitações associáveis ao estudo ora relatado. Inicialmente, convém evidenciar que foram utilizados os dados obtidos dos controles internos da entidade e das entrevistas informais com o gestor e o contador. Referidos dados, portanto, não foram "auditados", ou seja, não foram averiguados em termos de sua confiabilidade ou exatidão, assumindo-os como representativos da realidade empresarial em tela.

Por outro lado, por tratar-se de um estudo de caso, as conclusões citadas estão circunscritas à realidade da empresa pesquisada, não cabendo generalizações a respeito. Destarte, a aplicação dos mesmos procedimentos em outra escola, mesmo que de segmento assemelhado, pode requerer ajustes ou adequações ao novo contexto empresarial.

A terceira limitação a considerar diz respeito ao fato de não ter sido utilizado o conceito de margem de contribuição por fator limitante ou restritivo (Bornia, 2009; Martins, 2010), que eventualmente poderia alterar o resultado de alguma das turmas abrangidas.

Outra restrição está atrelada às limitações atribuídas pela literatura à Análise CVL e aos seus componentes, conforme comentado em seção precedente. Nesse sentido, as hipóteses simplificadoras requeridas para aplicar a Análise CVL são um entrave à qualidade das informações decorrentes. Porém, os autores deste estudo defendem que o diagnóstico que esta ferramenta gerencial proporcionou acerca de várias facetas da entidade pesquisada é suficiente para qualificá-la como um integrante essencial dos controles internos que um administrador deve dispor, independentemente do porte ou segmento de atuação da empresa.

Por último, é interessante sugerir que trabalhos futuros discutam as limitações dessa forma de análise em estudos de caso, bem como ampliem as aplicações da Análise CVL para segmentos empresariais ligados à prestação de serviços, tendo em vista a escassez de publicações acerca desta categoria de empresas. 
Gestão de Custos em Escola de Idiomas: Estudo de Caso com aplicação da Análise Custo/Volume/Lucro

Rodney Wernke, Lucas dos Santos Faccenda, Ivone Junges

Além disso, caberia discutir a influência de algum(ns) fator(es) restritivo(s) no âmbito do resultado operacional desse tipo de empreendimento educacional, visto que aspectos relacionados ao número de alunos por sala e/ou das horas disponíveis de trabalho dos professores podem acarretar alterações na lucratividade de determinadas turmas.

\section{REFERÊNCIAS}

Andrade, M. M. de. (2002). Como preparar trabalhos para cursos de pós-graduação: noções práticas. (5a ed.). São Paulo: Atlas.

Assaf Neto, A., \& Lima, F. G. (2009). Curso de administração financeira. São Paulo, Atlas.

Baesso, R. de S. (2008). Sistemas de custeio, tomada de decisão e criação de valor: o caso de uma pequena empresa do setor de ensino de idiomas. Simpósio de Gestão da Inovação Tecnológica, Brasília, DF, Brasil, 25.

Baldvinsdottir, G., Mitchell, F., \& Norreklit, H. (2010). Issues in the relationship between theory and practice in management accounting. Management Accounting Research, 21(2), 79-82.

Barton, T. L., Shenkir, W. G., \& Hess, J. E. (1995). Wyatt Earp, frontier accountant. The CPA Journal, 65(6), 48.

Bartz, D., Fanfa, I. P., Kappel, R. da S., \& Zonatto, V. C. da S. (2009). Aplicação gerencial da margem de contribuição em uma indústria de extração e beneficiamento de minérios. Congresso Brasileiro de Custos. Fortaleza, CE, Brasil, 16.

Bonacim, C. A. G., Nardi, P. C. C., Silva, R. L. M. da, Cruz Júnior, R., \& Bonizio, R. C. (2013). Investment projects in agribusiness: cost-volume-profit analysis considering uncertainty and risk. Custos e Agronegócios Online, 9(3), 27-48.

Bornia, A. C. (2009). Análise gerencial de custos: aplicação em empresas modernas. (2a ed.). São Paulo: Atlas.

Bruni, A. L., \& Famá, R. (2003). Gestão de custos e formação de preços: com aplicações na calculadora HP-12C e Excel. São Paulo, Atlas. 
Busan, G., \& Dina, I. C. (2009). Using cost-volume-profit analysis in decision making. Anais do Congres of University Petrosani Economics. Romênia, 9(3).

Colpo, I., Medeiros, F. S. B., Amorin, A. L. W., \& Weise, A. D. (2015). Análise do custovolume-lucro auxiliando na tomada de decisão: o caso de uma microempresa. Revista da Micro e Pequena Empresa, 9(3), 22-36.

Crozatti, J., Silveira, A. S., Pereira, D. G., \& Ferreira, T. S. (2012). O custo ABC e o resultado econômico da escola pública como critério para avaliação de desempenho da gestão da educação. Revista Iberoamericana de Contabilidad de Gestión, 10(20), 1-17.

Cunha, L. A. (1999). Reforma universitária em crise: gestão, estrutura e território. In: Trindade, H. (Org.). Universidade em ruínas: na república dos professores. Porto Alegre: Cipedes.

Cunha, P., Haussmann, D., \& Grieshaber, C. (2009). Aplicação do método de custeio $A B C$ em uma instituição privada de educação infantil. Revista de Contabilidade da UFBA, 3(2), 49-64.

D’Amato, C. L., Galvão, M., Villaça, N. A. G., Jorge, R. K., \& Tavares, Z. (2012). Curso básico de finanças: entendendo finanças de maneira prática e objetiva. São Paulo, Atlas.

Dalmonech, L. F., Martinez, A. L., Viana, A., \& Ferreira, C. J. S. (2003). Limitações da análise tradicional de custo-volume-lucro: repensando as hipóteses simplificadoras do modelo. Congresso Brasileiro de Custos, Guarapari, ES, Brasil, 10.

Durieux, A., Beuren, I. M., Sousa, M. A. B. de, \& Raupp, F. M. (2003). Proposta de sistema de custos para uma escola franqueada de idiomas: o caso da escola de idiomas Fisk. Congresso Brasileiro de Custos, Guarapari, ES, Brasil, 10.

Eberle, V., \& Colauto, R. D. (2015). Pressões institucionais e adoção do Balanced Scorecard: o caso de uma organização do setor elétrico do sul do Brasil. Contabilidade Vista \& Revista, 25(3), 95-120.

Etges, A. P. B. da S., Calegari, R., Rhoden, M. I. dos S., \& Cortimiglia, M. N. (2016). Using cost-volume-profit to analysis the viability of implementing a new distribution center. Brazilian Journal of Operations \& Production Management, 13(1), 44-50.

Fonseca, J. W. F. da. (2012). Elaboração e análise de projetos: a viabilidade econômico-financeira. São Paulo, Atlas. 
Gestão de Custos em Escola de Idiomas: Estudo de Caso com aplicação da Análise

Custo/Volume/Lucro

Rodney Wernke, Lucas dos Santos Faccenda, Ivone Junges

Garrison, R. H., Noreen, E. W., \& Brewer, P. C. (2001). Contabilidade gerencial. (9a ed.). Rio de Janeiro: LTC.

Gitman, L. J. (2004). Princípios de administração financeira. (10a ed.). São Paulo:Pearson Addison Wesley.

Gonçalves, B. do N., Cruz, V. L., Morais, R. S. de, Meirelles, J. M. da S., Barbosa Junior, R. de L., \& Peixoto, E. P. de A. (2014). Comparativo entre o custeio por absorção, custeio variável e o custeio abc em uma escola estadual. Congresso Brasileiro de Custos, Natal, RN, Brasil, 21.

Hansen, D. R., \& Mowen, M. M. (2001). Gestão de custos. São Paulo, Atlas.

Heusi, A. C. da S., Moraes, M. C. B., Raupp, F. M., \& Beuren, I. M. (2015). Determinação do cálculo do custo por vaga e matrícula efetiva em universidade pública. Revista Gestão Universitária na América Latina - GUAL, 8(3), 70-92.

Horngren, C. T., Foster, G., Datar, S. M., Rajan, M., \& Ittner, C. (2009). Cost accounting: a managerial emphasis. Thirteenth Edition, New Jersey, Prentice Hall.

Instituto de Pesquisas Data Popular (2014). Demanda de aprendizagem de inglês no Brasil. British Council. Recuperado de: $<$ https://www.britishcouncil.org.br/sites/default/files/demandas de aprendizagempe squisacompleta.pdf $>$. Acesso em: 06/junho/2017.

ludícibus, S., \& Mello, G. R. (2013). Análise de custos: uma abordagem quantitativa. São Paulo: Atlas.

Kisakürek, M. M., Kiliç, E., \& Yilmaz, A. (2011). Cost-Volume-Profit Analysis at angio department of the hospital of Cumhuriyet University. Eletronic Journal of Social Sciences, 10(37), 42-59.

Laureth, S. V., Wernke, R., Heberle, E. L., \& Rufatto, I. (2018). Análise custo/volume/lucro aplicada em supermercado de pequeno porte: estudo de caso. Brazilian Journal of Development, 4(3), 863-885.

Lima, L. A. M. de, \& Cunha, G. R. (2016). Gestão de custos e performance empresarial: a visão dos gestores de instituições de ensino superior. Revista Gestão Universitária na América Latina - GUAL, Florianópolis, 9(3), 21-44.

Lopes, L. V. M., Flor, C. N. M., Lima, M. Y. de G., Vieira, S. F. A., \& Baccaro, T. A. (2017). Custos, desempenho e estrutura educacional do Ensino Fundamental: uma análise em um município do interior do Paraná. ABCustos, 12(3), 26-44. 
Lukka, K. (2010). The roles and effects of paradigms in accounting research. Management Accounting Research, 21(2), 110-115.

Maher, M. (2001). Contabilidade de custos: criando valor para a administração. São Paulo: Atlas.

Marcousé, I., Surridge, M., \& Gillespie, A. (2013). Finanças. São Paulo: Saraiva.

Marques, K. C. M., Camacho, R. R., \& Alcantara, C. C. V. de. (2015). Avaliação do rigor metodológico de estudos de caso em contabilidade gerencial publicados em periódicos no Brasil. Revista Contabilidade \& Finanças - USP. São Paulo, 26(67), 27-42.

Martins, E. (2010). Contabilidade de custos. (10a ed.). São Paulo: Atlas.

Martins, E., \& Rocha, W. (2010). Métodos de custeio comparados: custos e margens analisadas sob diferentes perspectivas. São Paulo: Atlas.

Moraes, L. C., \& Wernke, R. (2006). Análise custo/volume/lucro aplicada ao comércio de pescados. Revista Contemporânea de Contabilidade, 1(6), 81-101.

Oliveira, A. A. A., Moura, E. L., \& Chaves, H. A. M. (2008). Análise das relações de custo-volume-lucro em ambientes com incertezas. In: Robles Jr., A. (org.). Contabilidade de custos: temas atuais. Curitiba, Juruá.

Oyadomari, J. C. T., Cardoso, R. L., Mendonça Neto, O. R., Antunes, M. T. P., \& Aguiar, A. B. (2013). Criação de conhecimento em práticas de controle gerencial: análise dos estudos internacionais. Advances in Scientific and Applied Accounting. São Paulo, 6(1), 4-30.

Padoveze, C. L., \& Takakura Júnior, F. K. (2013). Custo e preços de serviços: logística, hospitais, transporte, hotelaria, mão de obra e serviços em geral. São Paulo, Atlas.

Peleias, I. R. (2011). Contabilidade gerencial em empresas de pequeno e médio porte. In: Parisi, C., \& Megliorini, E. (Org.). Contabilidade gerencial. São Paulo, Atlas.

Rauen, F. (2015). Roteiros de iniciação científica: os primeiros passos da pesquisa científica desde a concepção até a produção e a apresentação. Palhoça, Editora UNISUL.

Richardson, R. J. (1999). Pesquisa social: métodos e técnicas. (3a ed.). rev. e ampl. São Paulo: Atlas. 
Sant'anna, M. M., Piacentini, N., Simões, R. S., Abreu, A. L., \& Kosztrzepa, R. (2013). Gestão estratégica de custos com o ABC: um estudo de caso na escola de educação profissional SENAI. Revista Ciências Sociais em Perspectiva, 12(23), 127.

Santos, J. J. (2005). Formação de preços e do lucro: custos marginais para formação de preços referenciais. São Paulo: Atlas.

Santos, L. A. dos, Marion, J. C., \& Kettle, W. M. (2014). Gestão estratégica de custos: um enfoque gerencial utilizando análise CVL na produção de leite da fazenda UNASP EC. Custos e Agronegócios Online, 10(3), 24-37.

Santos, L. dos, \& Bronnemann, M. R. (2013). Desafios da gestão em instituições de ensino superior: um estudo de caso a partir da percepção de diretores de centro de uma IES pública do sul do Brasil. Revista Gestão Universitária na América Latina GUAL, 6(1), 01-21.

Silva, R. N. S., \& Lins, L. S. (2017). Gestão de custos: contabilidade, controle e análise. (4a ed.). São Paulo, Atlas.

Silva, D. L. R. da, Benedicto, G. C. de, \& Salazar, J. N. A. (2005). Método de custeio baseado na Teoria das Restrições: um estudo de caso aplicado a franquias de escolas de idiomas. Congresso Internacional de Custos, Florianópolis, SC, Brasil, 9.

Soares, T. C., Mazon, G., \& Soares, A. N. (2011). Comparação internacional entre custos universitários. Revista Gestão Universitária na América Latina - GUAL, 4(2), 74-88.

Souza, B. C., \& Rocha, W. (2010). Modelo de análise de lucro na logística: conceitos importantes para as decisões. Revista Mundo Logística, 17(jul./ago.).

Souza, M. A. de. (2011). Mensuração e custeio: fundamentos de custos para gestão. In: Parisi, C., \& Megliorini, E. (org.). Contabilidade gerencial. São Paulo, Atlas.

Souza, M. A. de, \& Diehl, C. A. (2009). Gestão de custos: uma abordagem integrada entre contabilidade, engenharia e administração. São Paulo: Atlas.

Souza, M. A., Schnorr, C., \& Ferreira, F. B. (2011). Análise das relações custo-volumelucro como instrumento gerencial: um estudo multicasos em indústrias de grande porte do Rio Grande do Sul. Revista de Contabilidade e Organizações, 5(12), 109134. 
Sulaiman, M., Ahmad, N. N. N., \& Alwi, N. M. (2004). Management accounting practices in selected Asian countries: a review of the literature. Managerial Auditing Journal, 19(4), 493-508.

Wernke, R. (2010). Gestão de custos no comércio varejista. Curitiba: Juruá.

Wernke, R., Farias Júnior, S. P., Lembeck, M., \& Mendes, E. Z. (2011). Análise Custo/Volume/Lucro aplicada em escola infantil. Congresso Brasileiro de Custos, Rio de Janeiro, RJ, Brasil, 18.

Wernke, R. (2014). Custos logísticos: ênfase na gestão financeira de distribuidoras de mercadorias e de transportadoras rodoviárias de cargas. Maringá: Editora MAG.

Yin, R. K. (2005). Estudo de caso: planejamento e método. Porto Alegre: Bookman.

Yuan, F. C. (2009). The use of a fuzzy logic-based system in cost-volume-profit analysis under uncertainty. Expert Systems with Applications, 36(2), 1155-1163.

Zdanowicz, J. E. (2012). Finanças aplicadas para empresas de sucesso. São Paulo: Atlas.

Data de Submissão: 07/11/2017

Data de Aceite: 28/06/2018 